\title{
CHRIS HEYDE: AN APPRECIATION
}

Chris Heyde succeeded Joe Gani as Editor-in-Chief of the Applied Probability journals in 1990, and soon afterwards Chris and Joe appointed me as Executive Editor to manage the Applied Probability Trust's publishing office. Joe had founded the journals and established the office at the University of Sheffield in 1965 while chairman of the Department of Probability and Statistics. After 1974, the Editors-in-Chief were based outside Britain, although (as our readers will know) editorial decisions and journal production have continued to be implemented from Sheffield.

Chris's professorial appointments at ANU and Columbia meant that several time zones separated the Chief Editor from the publishing office. This made effective distance communication more important than ever in maintaining the success of the Applied Probability journals in a climate of rapidly changing publishing technology and user expectations. Communications with Sheffield had to support fast editorial turnaround, while compensating as far as possible for live editorial meetings. Chris met this considerable challenge through the rigorous requirements of his two-way reporting schedule. For the next 16 years, despite the heavy load of his other professional activities, his editorial decisions, advice, and comments arrived in the Executive Editor's inbox with unfailing regularity. It was Chris's clarity, authority, decisiveness, and consistent judgement as Editor that securely underpinned the editorial quality of the journals. His respect for scholarly standards was unwavering, but it coexisted with a humane understanding and a sense of fairness that found solutions to the most difficult editorial problems.

Developments in information transfer at this time that allowed us to modernize the Trust's publishing also improved our editorial efficiency. Electronic mail for example allowed some much-valued real-time communication, at least during Chris's semesters at Columbia, but the number of messages that were timed far into the early hours attested to the weight of his workload. Despite his extensive commitments in teaching, research, and administration, Chris was not deflected from his self-imposed response deadlines unless the reasons were compelling. During the devastating Australian bushfires of January 2003, fire threatened the forested suburb of Canberra where Chris and Beth lived. On this rare occasion, Chris was out of contact: he was spending several days on the roof of his house on firewatch.

The unique landscapes of Australia were close to Chris's heart. Whenever time for vacation could be found, he and Beth would set off for their summer home on the New South Wales coast, or on more extensive exploration into the outback. If long travel leave was in prospect, Chris laid careful prior plans for maintaining his editorial communications, even if at first the available technology was basic. One of his first long expeditions crossed a particularly remote part of northern Australia where the widely-scattered settlements had little telecommunications access. Chris confirmed that they did however have a regular postal service, and before leaving home he set up poste-restantes along this part of his route. On a prearranged schedule, we airmailed from Sheffield packages of documents for Chris's decision. Thanks to Australia Post, the mail packages were waiting for Chris at each mail stop. His responses came back to Sheffield as soon as he reached a centre large enough to have a fax service, and in reality the message turnaround was delayed by only a few days. A subsequent expedition marked an increase in sophistication when Chris took a laptop computer for the first time-unfortunately for this experiment, the computer electronics did not survive the conditions of the Australian desert. 
Within a short time, of course, these limitations were overcome by developments in technology that offered the same communications access whether Chris was travelling in the remote wilderness or was at his university workplace. Nevertheless, Chris acted on his belief that, in order for good contact to be maintained with Applied Probability Trust operations, remote communication had to be complemented by face-to-face conference. In spite of the constraints of long-distance travel and his own crowded schedule, Chris successfully found opportunities for the editorial meetings which supplied an essential dimension outside the limitations of email communication.

After dealing with business agendas, Chris off-duty would emerge as a most genial host, a sympathetic listener, and an engaging conversationalist with a keen eye for life's comic as well as its serious moments. His interests ranged widely. After one meeting at Columbia, he suggested a tour of nearby St John's Episcopal Cathedral. Here he revealed an extensive knowledge of the huge landmark building: its complex construction history, the mathematics of Gothic architecture, and its acoustics as a musical performance venue. Beyond the factual, however, Chris was interested in a more complex question, one perhaps not immediately related to mathematics: the changing role and the future function of a purpose-built structure such as this in relation to historic changes in local communities and neighbourhoods.

The Festschrift for Chris Heyde, Stochastic Methods and Their Applications [1], was published by the Applied Probability Trust to celebrate Chris's 65th birthday in 2004. I had the privilege of taking the first copies from our printers in Britain to Canberra. The presentation banquet in the Great Hall of University House was a memorable event that brought together many of Chris's friends, associates, and colleagues: sadly, it was also to be the last time that some of us were to see him.

Chris continued his active role as Editor until 2007. By early 2008, health considerations finally obliged him to step down, and Søren Asmussen, who had become Co-Editor-in-Chief in 2005, assumed sole editorship.

In one of his last editorial messages to Sheffield, sent just before his final illness, Chris promised soon to deliver his report on a journal submission that he had identified earlier for his personal review. He was especially interested in the subject of the paper, but he also wanted to encourage the beginning author to optimize a first research contribution. These motivations were entirely characteristic of Chris, and it was equally typical of his courage and commitment that he had every intention of completing the task in the face of failing health. Chris's untimely passing is an enormous loss to all who knew him: those of us who worked with him in his editorial role will remember him especially for the scientific integrity and discernment by which he consolidated Joe Gani's original vision for the Applied Probability journals.

The Applied Probability Trust is privileged to have Søren continue the stewardship. I and my colleagues in the Sheffield office have the great satisfaction of supporting Søren as Editor with an effective and respected publishing system, founded by Joe, to which Chris in turn made such a memorable contribution.

Applied Probability Trust

L. NASH

University of Sheffield

\section{References}

[1] Gani, J. M. and Seneta, E. (eds) (2004). Stochastic Methods and Their Applications. J. Appl. Prob. Spec. Vol. 41A, Applied Probability Trust, Sheffield. 